\title{
Staining properties and stability of a standardised Romanowsky stain
}

\author{
P. N. MARShALL ${ }^{1}$, S. A. BENTLEY ${ }^{2}$, AND S. M. LEWIS
}

From the Department of Haematology, Royal Postgraduate Medical School, Hammersmith Hospital, Du Cane Road, London W12 OHS, UK

SUMMARY An evaluation of the standardised Romanowsky stain of Marshall et al. has been made in a routine haematology laboratory. It was noted that this stain had several advantages over the $\dot{\omega}$ May-Grünwald Giemsa stain used in most British laboratories. These advantages include ease and $\mathrm{N}_{\infty}$ speed of preparation, a shorter staining time, and reproducibility of results. These results are described in detail. The stability of the stock stain solution and of the 'working' stain (stock + buffer) has been studied by, respectively, thin-layer chromatography and visible spectroscopy. No $\bar{z}$ change was detected in the composition of the stock solution at ambient temperature over a period of six months. Stability was unaffected by the composition of the container (polyethylene, Pyrex TM,, or soda-glass) or by daylight. The 'working' solution was stable for 3 hours. Thereafter a precipitate is formed, consisting of thiazine dyes and eosin in a molar ratio of $\sim 2: 1$.

The major problem in the use of Romanowsky stains is batch-to-batch variation in their staining performance. This is a potential source of diagnostic error. Adoption of a reliable, standardised stain would not only eliminate such error but would also ensure comparability of stained films from different laboratories and facilitate reference to illustrative atlases. Moreover, such a stain is essential for use with automatic cell recognition systems. Variability in performance is usually due to variation in stain composition (Scott and French, 1924; Lillie and Roe, 1942; Lillie, 1943a, 1944a; Saal, 1964; Clemens and Toepfer, 1968; Toepfer, 1972; Marshall and Lewis, 1974b, 1975a; Löhr et al., 1975; Marshall et al., 1975a,b,c; Wittekind and Löhr, 1975; Wittekind $e t$ al., 1976). We have therefore developed a stain prepared from pure dyes, which is of constant composition and performance (Marshall et al., 1975c). Since our original report, in which the staining properties of different cell types were illustrated, we have continued to study the stain's properties. In this paper we describe its performance in routine use, list its staining properties, and provide data on its stability.

${ }^{1}$ Present address and address for correspondence: Coulter Biomedical Research, 40 Bear Hill Road, Waltham, MA 02154, USA.

${ }^{2}$ Present address: Room 4D22, Building 36, National Institutes of Health, Bethesda, MD 20014, USA.

Received for publication 25 July 1977

\section{Material and methods}

PREPARATION OF STAIN AND STAINING TECHNIQUE

Dyes were purified, as described previously (Marshall et al., 1975c; Marshall and Lewis, 1975b). The stock solution of stain was prepared and used as described by Marshall et al. (1975c).

Stained preparations were made from most of the $\frac{\overline{0}}{0}$ blood and bone-marrow samples arriving in our laboratory during one working week, approximately 1000 specimens in all. Duplicate preparations were $ᄋ$ made by our routine May-Grünwald Giemsa (MGG) technique (Dacie and Lewis, 1975).

\section{STABILITY OF STAIN}

The stock solution was stored at ambient tempera- $N$ ture $\left(\sim 21^{\circ} \mathrm{C}\right)$ in polyethylene, Pyrex ${ }^{\text {TM }}$, and soda- $N$ glass containers, in darkness and in daylight. All containers were tightly stoppered to prevent evapora- $\omega$ tion but were only partially filled to allow contact of the stain with atmospheric oxygen. Aliquots ofe stain were withdrawn at intervals over a period of six $\overline{\mathscr{D}}$ months, diluted with methanol, and analysed by ${ }^{+}$ thin-layer chromatography (Marshall and Lewis, $\frac{T}{O}$ 1974a). The stability of the 'working' stain (stock $+\frac{\vec{D}}{\square}$ buffer) was investigated as follows: samples were prepared and aliquots withdrawn at intervals of up르 to eight hours. Where necessary, these were centrifuged to remove precipitate, the supernatant was 
diluted with excess methanol, and visible absorption spectra were made using a Unicam SP 800 Recording Spectrophotometer.

\section{Results and discussion}

During the test period, peripheral blood and bonemarrow films were examined from patients with a wide variety of disorders. The staining appearances of the vast majority of normal and pathological cell types were thus seen. With the standardised stain red cells stained a clear pink, in contrast to a brownish hue in our MGG preparations. The transition from basophilic through polychromatic to orthochromatic erythroblast was clearly demonstrated, as was the presence of red cell inclusions such as Howell-Jolly bodies and siderotic granules. Malarial parasites showed characteristic Romanowsky staining reactions.

In white cells, the specific granules of neutrophils, eosinophils, and basophils were well stained, as were the azurophil granules of lymphocytes and monocytes, the primary granules of promyelocytes, and platelet granules. Toxic granulation of neutrophils was shown clearly. The stain gave an excellent range of colouration in the mononuclear cells; cytoplasm was grey in monocytes, a clear pale blue in lymphocytes, a deeper blue in blast cells and atypical mononuclear cells, and a rich dark blue in plasma cells and proerythroblasts. Nuclear chromatin patterns were well stained and nucleoli were very clearly demonstrated.

The appearances observed were thus in all respects those of an excellent Romanowsky stain, and the results were comparable with the best MGG preparations. The latter will, of course, vary with the batches of stain used (see, for example, Marshall et al. (1975a) and Toepfer (1972)) whereas our stain is of constant composition and therefore gives consistent results.

Analysis of the stock solution of our stain showed that its composition remained unchanged in the sixmonth period under all conditions of storage. The thiazine dyes underwent no oxidative demethylation even though solutions were in contact with atmospheric oxygen. There are few comparable data on other Romanowsky stains. Lillie (1944b) measured the changes in the visible absorption spectra of methylene blue-eosinate and Wright's stain with time. The stains were found to be highly stable in glycerol-methanol $(1: 1 \mathrm{v} / \mathrm{v})$, and this solvent mixture was therefore selected for our stain. Stock solutions, which are totally methanol-based, are much less stable (Lillie, 1944b; Dean et al., 1977). These include the stains of Jenner, Leishman, May-Grünwald, and the more recent stain of Wittekind et al. (1976).

Our 'working' solution proved stable in use for three hours. Thereafter, the formation of a precipitate made it necessary to prepare a fresh solution. Stain precipitation was investigated quantitatively by visible spectroscopy. Solutions of the 'working' stain diluted with methanol showed two absorption maxima, one at $642 \mathrm{~nm}$ due to the thiazine dyes (methylene blue and azure B), and another at 525 $\mathrm{nm}$ due to eosin. Thus, by measuring the reduction in the absorbances at these wavelengths, it was possible to follow the amount and composition of the precipitate formed. It was found that the solution was stable for three hours (Figure). After this, significant amounts of precipitate were formed, the rate of formation being greatest three to four hours after preparation. Precipitation ceased at eight hours, when the concentration of eosin was effectively zero. The composition of this precipitate was deduced as follows: the 'working' solution contains thiazine dyes and eosin in the ratio of $2: 1$ by weight. Taking the molecular weight of the thiazine dyes as 350 (the molecular weight of the predominant dye, azure B hydrobromide - that of methylene blue hydrochloride is not significantly different) and that of eosin (colour acid) as 648 (ignoring the small proportion of $2^{\prime}, 4^{\prime}, 5^{\prime}$-tribromofluorescein), we see that in the freshly prepared 'working' solution the cationic and anionic dyes are present in the molar ratio of about 3.7:1. By eight hours the concentration of the cationic dyes in solution has been halved, whereas the

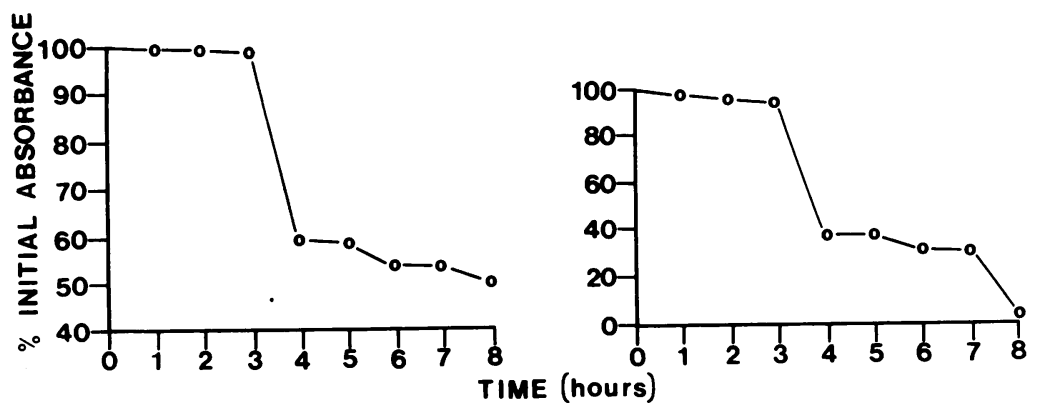

Figure Stability of 'working' solution of the stain: (left) change of absorbance at 642 nm (thiazine dye absorption maximum) with time; (right) change of absorbance at 525 $n m$ (eosin absorption maximum) with time. 
concentration of eosin has fallen to virtually zero. Therefore, the molar ratio of thiazine dyes:eosin in the precipitate is about $2: 1$. Similar studies on the 'working' solutions of commercially available stains indicate the formation of similar precipitates, the rate of formation again being greatest three to four hours after dilution of the stock.

In practical terms, the standardised stain has several advantages in the routine laboratory. In addition to its stability, no lengthy process of dissolution of dyes and ageing of solutions is necessary. Filtration of the stock solution is not required, and the staining time is considerably shorter than in the routine MGG technique. This can produce a significant saving of time when slides are stained intermittently during the day, while providing for the emergency service a simple staining procedure that gives results equal to those obtained with optimal technical facilities. It is probable that the stain will be commercially available in the near future.

This work was assisted by a grant from the Department of Health and Social Security. Mr W. Johns provided skilful technical assistance.

\section{References}

Clemens, H. J., and Toepfer, K. (1968). Physikalischchemische Eigenschaften von kommerziellen Thiazinfarbstoffen 2. Qualitative und quantitative Untersuchungen über die Verunreinigungen der Farbstoffe und das 'Umlösen' zum Erhalt eines höheren Reinheitsgrades. Acta Histochemica. Zeitschrift für histologische Topochemie, 31, 126-134.

Dacie, J. V., and Lewis, S. M. (1975). Practical Haematology, 5th edition, pp. 70-72 and 73. Churchill Livingstone, London.

Dean, W. W., Stastny, M., and Lubrano, G. J. (1977). The degradation of Romanowsky-type blood stains in methanol. Stain Technology, 52, 35-46.

Lillie, R. D. (1943a). Blood and malaria parasite staining with eosin azure methylene blue methods. American Journal of Public Health, 33, 948-951.

Lillie, R. D. (1943b). A Giemsa stain of quite constant composition and performance, made in the laboratory from eosin and methylene blue. Public Health Reports (Washington), 58, 449-452.

Lillie, R. D. (1944a). Factors influencing the Romanowsky staining of blood films and the role of methylene violet. Journal of Laboratory and Clinical Medicine, 29을 1181-1197.

Lillie, R. D. (1944b). The deterioration of Romanowskyes stain solutions in various organic solvents. Publico Health Reports (Washington), Supplement, 178, 1-16. 등 Lillie, R. D., and Roe, M. A. (1942). Studies on poly chrome methylene blue I. Eosinates, their spectra and staining capacity. Stain Technology, 17, 57-63.

Löhr, W., Grubhofer, N., Sohmer, I., and Wittekind, D心 (1975). The azure dyes: their purification and physicochemical properties. II. Purification of azure B. Stain Technology, 50, 149-156.

Marshall, P. N., Bentley, S. A., and Lewis, S. M. (1975a) An evaluation of some commercial Romanowskȳ stains. Journal of Clinical Pathology, 28, 680-685.

Marshall, P. N., Bentley, S. A., and Lewis, S. M. (1975b) A procedure for assaying commercial samples of eosin $\omega$ Stain Technology, 50, 107-113.

Marshall, P. N., Bentley, S. A., and Lewis, S. M. (1975c) A standardised Romanowsky stain prepared from purified dyes. Journal of Clinical Pathology, 28, 920-923.Marshall, P. N., and Lewis, S. M. (1974a). A rapid thin 3 layer chromatographic system for Romanowsky blooक्क stains. Stain Technology, 49, 235-240.

Marshall, P. N., and Lewis, S. M. (1974b). Batch varia $\vec{\imath}$ tions in commercial dyes employed for Romanowsky $-\infty$ type staining: a thin-layer chromatographic study Stain Technology, 49, 351-358.

Marshall, P. N., and Lewis, S. M. (1975a). Metal con taminants in commercial thiazine dyes. Stain Tech nology, 50, 143-147.

Marshall, P. N., and Lewis, S. M. (1975b). The purifica tion of methylene blue and azure $\mathrm{B}$ by solvent extrac tion and crystallization. Stain Technology, 50, 375-381음

Saal, J. R. (1964). Giemsa stain for the diagnosis of bovine babesiosis. I. Staining properties of commerciat samples and their component dyes. Journal of Protozoology, 11, 573-582.

Scott, R. E., and French, R. W. (1924). Standardization of biological stains. Military Surgeon, 55, 229-243.

Toepfer, K. (1972). Analyse der May-Grünwald-Giemsafärbung als Beitrag zur Notwendigkeit des Arbeiten§ mit reinen, definierten Farbstoffen. Verhandlungen de deutschen Gesellschaft für innere Medizin, 78, 272-276은

Wittekind, D., Kretschmer, V., and Löhr, W. (1976) Kann Azur B-Eosin die May-Grünwald-Giemsa음 Färbung ersetzen ? Blut, 32 71-78.

Wittekind, D., and Löhr, W. (1975). Purification standardization and quality control of Romanowsky dyes. Chapter 12 in Quality Control in Haematology Symposium of the International Committee for Standw ardization in Haematology, edited by S. M. Lewis ane J. F. Coster. Academic Press, London. 